\title{
Evaluación de la Contaminación Microbiológica Presente en los Arroyos La Carolina y La Totora Ubicados en el Partido de Gral. Alvarado. Prov. de Buenos Aires. Argentina.
}

Evaluation of the Microbiological Contamination Present in La Carolina and La Totora Streams Located in Gral. Alvarado, Country Buenos Aires, Argentina.

\section{Marina A. Maggiore}

Universidad Tecnológica Nacional - Facultad Regional Mar del Plata - Argentina mamaggi3@hotmail.com

\section{Mariana G. Rampi}

Universidad Tecnológica Nacional - Facultad Regional Mar del Plata - Argentina rampimariana@gmail.com

\section{Natalia R. Cuestas}

Universidad Tecnológica Nacional - Facultad Regional Mar del Plata - Argentina nataliarcuestas@gmail.com

\section{Macarena Campins}

Universidad Tecnológica Nacional - Facultad Regional Mar del Plata - Argentina macarenacampins@gmail.com 


\title{
Resumen
}

La contaminación fecal de las aguas superficiales es un problema que incide directamente en la salud humana. El indicador más significativo entre la exposición a aguas ambientales y riesgo de enfermedad es Escherichia coli. El objetivo del trabajo fue evaluar la contaminación ambiental y el riesgo sanitario en los arroyos La Carolina y La Totora, entre julio 2016 y junio 2017, utilizando como indicadores a los Coliformes totales, Coliformes fecales (CF), E. coli y Enterococos fecales (EF). Los análisis se llevaron a cabo siguiendo lo descripto en Standard Methods. Los resultados obtenidos fueron similares en ambos arroyos, se presentaron los mayores recuentos en enero, febrero y marzo del 2017. Si bien, los resultados no presentan valores relevantes, se puede concluir que en casi la totalidad de los muestreos, los resultados de CF, E. coli y EF fueron superiores a los valores guía de la Resolución 42/06 del ADA.

Palabras claves: contaminación, aguas superficiales, coliformes, enterococos fecales

\begin{abstract}
Fecal contamination of surface water is a problem which directly affects human health. The most significant indicator of disease risk from surface water is Escherichia coli. The objective of this paper was to evaluate environment contamination and sanitary risk in La Carolina and La Totora streams, between July 2016 and June 2017, using total coliform, fecal coliform, E. coli and Enterococcus faecales as indicators. Analysis were done according to the methods described in the Standard Methods. Result were similar in both streams, presenting the highest enumeration in January, February and March of 2017. Although, results do not present relevant data, it can be concluded that in most of the samples, the results of fecal coliform, E. coli and Enterococcus faecales were higher than the guide values from the ADA resolution 42/06.
\end{abstract}

Key Word: contamination, surface water, coliforms, fecal enterococci

\section{INTRODUCCIÓN}

Las fuentes de agua superficial son un eje fundamental en el desarrollo de los seres humanos, que permiten el abastecimiento para las diferentes actividades socioeconómicas llevadas a cabo en la sociedad; no obstante, de forma paradójica muchas de estas actividades causan alteración y deterioro de las mismas (ONU, 
1992).

Los principales contaminantes del agua son: Los agentes patógenos, bacterias, virus, protozoarios ó parásitos que entran al agua, provenientes de desechos orgánicos (Martínez Romero et al., 2009).

El control de la calidad sanitaria de los recursos del ambiente puede llevarse a cabo mediante la enumeración de bacterias indicadoras de contaminación fecal. Estas bacterias pueden ser utilizadas para valorar la calidad de los alimentos, sedimentos y aguas destinadas al consumo humano, la agricultura, la industria y la recreación. No existe un indicador universal, por lo que se debe seleccionar el más apropiado para la situación específica en estudio (Bachoon et al., 2010; Luby et al., 2008).

Los microorganismos indicadores son aquellos que tienen un comportamiento similar a los patógenos en cuanto a concentración en las aguas y reacción frente a factores ambientales, pero son más fáciles, rápidos y económicos de identificar (Méndez et al., 2010). Una vez que se ha demostrado la presencia de estos grupos indicadores, se puede inferir qué microorganismos patógenos se encuentran presentes (Del Pilar et al., 2005; Ávila de Navia y Estupiñan, 2009).

Los indicadores de contaminación fecal más utilizados son los coliformes totales y termotolerantes, Escherichia coli y enterococos (Rossen et al., 2008). El grupo de microorganismos coliformes es adecuado como indicador de contaminación fecal debido a que estos forman parte de la microbiota normal del tracto gastrointestinal, tanto del ser humano como de los animales homeotermos y están presentes en grandes cantidades en él. Los microorganismos coliformes constituyen un grupo heterogéneo de amplia diversidad en términos de género y especie. Todos los coliformes pertenecen a la familia Enterobacteriaceae (Santiago Rodriguez et al., 2012; Delgado et al., 2008).

Los coliformes totales se definen como bacterias Gram negativas en forma bacilar que fermentan la lactosa a temperatura de 35 a $37^{\circ} \mathrm{C}$ y producen ácido y gas (CO2) en $24 \mathrm{~h}$, aerobias o anaerobias facultativas, son oxidasa negativa, no forman esporas y presentan actividad enzimática ß-galactosidasa. Entre ellas se encuentran Escherichia coli, Citrobacter, Enterobacter y Klebsiella (Carrillo y Lozano, 2008; Larrea-Murrell et al., 2013).

Los coliformes termotolerantes (CTt), denominados así porque soportan temperaturas hasta de $45^{\circ} \mathrm{C}$, comprenden un número muy reducido de microorganismos, los cuales son indicadores de calidad por su origen. En su mayoría están representados por E. coli, pero se pueden encontrar de forma menos frecuente las especies Citrobacter freundii y Klebsiella pneumoniae. Estas últimas forman parte de los coliformes termotolerantes, pero su origen normalmente es ambiental (fuentes de agua, vegetación y suelos) y solo ocasionalmente forman parte de la microbiota normal (Santiago Rodriguez et al., 2012; Badgley et al., 2011). Por esto algunos autores plantean que el término de coliformes fecales, comúnmente utilizado, debe ser sustituido por coliformes termotolerantes (Chiroles et al., 2007; Narváez et al., 2008; Larrea-Murrell, et al., 2013, Ministerio de agua, Córdoba, 2016).

Los enterococos pueden estar presentes en suelo, alimentos, agua, plantas, animales e insectos (Köhler W, 2007) y suelen considerarse buenos indicadores de contaminación fecal debido a que son muy resistentes a condiciones adversas 
como la congelación y la desecación (Díaz et al., 2010; Yamahara et al., 2009). El uso de Enterococcus como un indicador de contaminación fecal de aguas con fines recreativos fue recomendado por la Agencia de Protección Ambiental de los Estados Unidos (USEPA, de las siglas en inglés) en 1986 (Díaz et al., 2008).

El objetivo del presente trabajo fue evaluar la contaminación ambiental y el riesgo sanitario, utilizando como indicadores a los Coliformes totales (CT), Coliformes fecales (CF) o coliformes termotolerantes (CTt), Escherichia coli y Enterococos fecales (EF), antiguamente llamados estreptococos fecales, en los arroyos La Carolina y La Totora y su importancia como sitios puntuales de contaminación en la playa adyacente.

Dichos arroyos se encuentran en las ciudades de Miramar y Mar del Sud ambas localizadas en el Partido de General Alvarado. La ciudad de Miramar es cabecera del partido, se encuentra ubicada sobre el litoral atlántico S.E. de la Provincia de Buenos Aires, emplazada entre las cuencas de los arroyos El Durazno, La Totora y Las Brusquitas, situadas en la porción nororiental del partido de General Alvarado, siendo este último arroyo el límite administrativo con el Partido de General Pueyrredón. (Martín et al., 2009.) La ciudad de Miramar se fundó sobre las márgenes del arroyo El Durazno, mientras que Mar del Sud se encuentra atravesado por los arroyos La Tigra y La Carolina. Las principales actividades económicas se centran en la explotación agrícola-ganadera y el turismo de sol y playa durante el verano. (Del Rio et al., 2017.).

\section{MATERIALES Y MÉTODOS}

Se realizaron muestreos periódicos durante el período comprendido entre julio 2016 y junio 2017, con el fin de evaluar las cuatro estaciones climáticas.

\section{Descripción del área de estudio y puntos de muestreo:}

La planicie costera del Partido de General Alvarado es ligeramente ondulada y surcada por arroyos (Las Brusquitas, El Durazno, La Totora, La Ballenera, La Carolina y La Tigra), que en la costa forma acantilados de pequeña altura. (Islas, 2003). El arroyo La Totora se encuentra entre las localidades de Miramar y Mar del Sur. Por otro lado, el arroyo La Carolina se localiza al norte de la ciudad de Mar del Sur.

Los puntos de muestro fueron los siguientes:

- $\quad$ LT 77: Arroyo La Totora en su intersección con la ruta $\mathrm{N}^{0} 77$.

- $\quad$ LT 11: Arroyo La Totora en su intersección con la ruta $\mathrm{N}^{\circ} 11$ (próximo a su desembocadura).

- $\quad$ LC 11: Arroyo La Carolina en su intersección con la ruta $\mathrm{N}^{\circ} 11$.

- $\quad$ LC D: Arroyo La Carolina en su desembocadura

Entre los puntos de muestreo LT 77 y LT 11, el arroyo atraviesa zona 
agrícola-ganadera. Mientas que entre los puntos de muestreo LC 11 y LC D el arroyo atraviesa zona agrícola y zona urbana poco poblada (Figura 1).

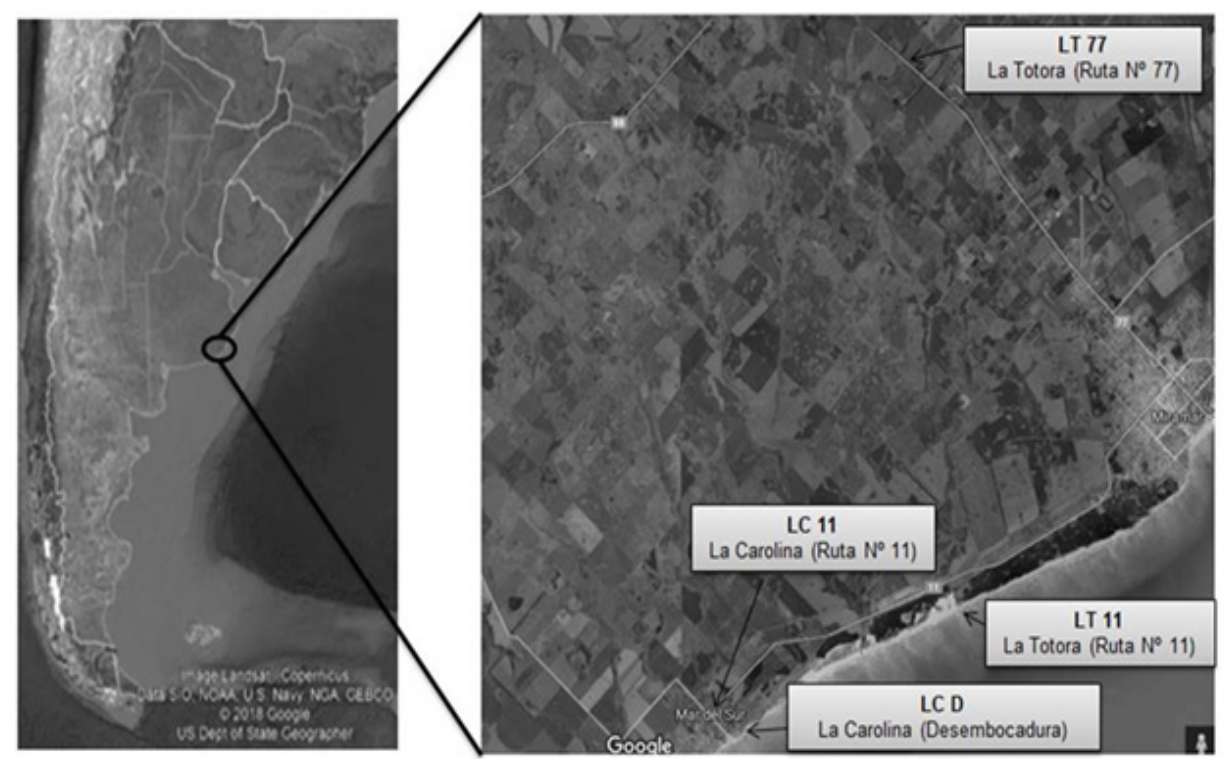

Figura 1- Ubicación geográfica de los arroyos y puntos de muestreo

\section{Muestreo y transporte de muestras:}

En cada punto de muestreo se recolectó la muestra utilizando botellas esterilizadas de $250 \mathrm{ml}$ con tapa a rosca, las cuales fueron transportadas refrigeradas en un lapso no mayor de 4 horas al laboratorio de Análisis Industriales de la Universidad Tecnológica Nacional, Facultad Regional Mar del Plata, y analizadas el mismo día del muestreo.

\section{Métodos de análisis y bacterias utilizadas:}

Los parámetros microbiológicos analizados fueron: Coliformes Totales (CT), Coliformes Fecales (CF), Enterococos Fecales (EF) y presencia de E. coli. Se aseguró la conservación de las muestras desde el punto de muestreo hasta su ingreso al laboratorio.

- Coliformes: para la cuantificación de bacterias coliformes totales y fecales se aplicó el método de Tubos múltiples (NMP) (Apha, 2012). De esta forma, se inocularon $10 \mathrm{ml}$ de la muestra madre en una serie de 5 tubos que contenían caldo Laurilsulfato triptosa (Biokar Diagnostic, Francia) a doble concentración con la 
campanita de Durham en posición invertida. Las distintas diluciones se inocularon en series de 5 tubos que contenían $10 \mathrm{ml}$ de caldo Laurilsulfato triptosa (Biokar Diagnostic, Francia) simple concentración con campanita de Durham. Todos los tubos se incubaron a $35^{\circ} \mathrm{C}$ por un lapso de $48 \mathrm{~h}$. Transcurrido el periodo de incubación, se consideró positiva aquella muestra que presentó turbidez y producción de gas en el interior de la campana de Durham. Para la cuantificación de coliformes totales, las muestras positivas fueron repicadas en caldo bilis verde brillante (Biokar Diagnostic, Francia) a $35^{\circ} \mathrm{C}$ por 48 h. Posterior al periodo de incubación, las muestras positivas (turbiedad y producción de gas) se repicaron en caldo EC (Biokar Diagnostic, Francia) a 44,5 $5^{\circ}$ por 24 h, cuantificando de esta forma el NMP de coliformes fecales según Apha (2012).

- Esherichia coli: de la prueba confirmativa en caldo EC se tomaron inóculos de los tubos positivos y se repicaron en caldo triptofano (Biokar Diagnostic, Francia). Los mismos se incubaron a $44.5^{\circ} \mathrm{C}$ por $24 \mathrm{~h}$. Transcurrido el periodo de incubación, los tubos fueron sometidos a una identificación presuntiva, mediante la prueba bioquímica de producción de indol. Para la confirmación se clonaron en agar tripteina soya (Biokar Diagnostic, Francia) y se les realizó las pruebas de rojo de metilo (RM), Voges Proskauer (VP) y metabolización de citrato (C), conocido como IMViC y el TSI, según Apha (2012) y Faddin (2003).

Enterococos fecales: para la cuantificación de enterococos fecales se aplicó el método de Tubos múltiples (NMP) (Apha 2012). De esta forma, se inocularon $10 \mathrm{ml}$ de la muestra madre en una serie de 5 tubos que contenían caldo Azida Dextrosa (Biokar Diagnostic, Francia) a doble concentración. Las distintas diluciones se inocularon en series de 5 tubos que contenían $10 \mathrm{ml}$ simple concentración del caldo Azida dextrosa. Todos los tubos se incubaron a $35^{\circ} \mathrm{C}$ por un lapso de 48 h. Transcurrido el periodo de incubación, se consideró positiva aquella muestra que presentó turbidez y sedimentación de color blanca. Para la confirmación de Enterococos fecales, las muestras positivas fueron repicadas en caldo Ethyl Violet Azide - EVA (Biokar Diagnostic, Francia) a $35^{\circ} \mathrm{C}$ por $48 \mathrm{~h}$. Posterior al periodo de incubación, a aquellas muestras positivas, que presentaron precipitación de color violeta se les realizó la observación al microscopio binocular Arcano XSZ 100 BN con el objetivo de inmersión según Apha (2012).

\section{RESULTADOS Y DISCUSIÓN}

Los resultados obtenidos en el arroyo La Totora se observan en los Gráficos $\mathrm{N}^{\circ}$ 1 al 6. En los mismos podemos observar que los recuentos de CT más elevados, se presentaron en el mes de agosto de 2016 en el punto LT77 y en marzo de 2017, los valores 50 x $103 \mathrm{NMP} / 100 \mathrm{ml}$ y 30 x $103 \mathrm{NMP} / 100 \mathrm{ml}$ respectivamente, como puede verse en el Gráfico $\mathrm{N}^{\circ} 1$.

Con respecto al recuento de CF y E. coli, los mismos presentaron sus valores más elevados en marzo del 2017 para ambos parámetros en el punto LT77, este valor fue de 13 x $103 \mathrm{NMP} / 100 \mathrm{ml}$ en ambos casos. Mientras que en el punto LT11 el pico más elevado de CF se presentó en enero de 2017 con un valor de 14 x 103 NMP/100 ml y el correspondiente a E. coli ocurrió en el mes de marzo de 2017 con un valor de 40 x $102 \mathrm{NMP} / 100 \mathrm{ml}$ (Gráfico $\mathrm{N}^{\circ} 2$ y 3). 
Los Enterococos fecales presentaron un notorio aumento en enero de 2017 con un resultado de $80 \times 102 \mathrm{NMP} / 100 \mathrm{ml}$ en el punto LT 77 (más alejado a la desembocadura) y en marzo del 2017 en el punto LT 11, el valor el mismo fue de 24 x 103 $\mathrm{NMP} / 100 \mathrm{ml}$ (Gráfico No 4).

Es importante remarcar que el empleo de la relación E. coli/Enterococos (EC/E) puede ser de gran utilidad para la determinación del origen de la contaminación. Se ha sugerido que las cantidades de E. coli y enterococos fecales que son descargados por los seres humanos son significativamente diferentes a las descargadas por los animales (Tchobanoglous et al., 2003; Meeroff et al., 2008). Cuando el cociente $\mathrm{EC} / \mathrm{E}$ es $>4$ se está en presencia de una contaminación fecal de origen humano, y cuando este cociente es $<0,7$ es de origen animal. Sin embargo, en el intervalo entre 0,7 y 4 , al no poder interpretar el origen, se considera contaminación mixta (Marchand, 2002; Coyne y Howell et al., 1994). Con respecto a los resultados obtenidos en el arroyo La Totora, podemos indicar que en 14 muestreos (63.9\%) se observó contaminación de origen animal, 5 muestreos (22.7 \%) presentaron contaminación mixta, mientras que solo 3 muestreos (13.7\%) presentaron un origen humano de la contaminación (Gráfico $\mathrm{N}^{\circ} 7$ ). Lo cual coincide con la actividad principal de la zona.

En los Gráficos $\mathrm{N}^{0} 5$ y 6 podemos observar cómo se manifiestan los cuatro parámetros de investigación a lo largo del tiempo en cada punto de muestreo.

Existen diversas normativas para evaluar la calidad de aguas recreacionales, por ejemplo, la Resolución 42/06 del Directorio de la Autoridad del Agua de la Prov. de Buenos Aires, enumera los valores de referencia de calidad de aguas dulces y marinas para protección de la biota acuática, recreación y de calidad de aguas dulces como fuente de agua para su potabilidad en la zona de uso exclusivo del Río de la Plata y su frente marítimo. En la misma se presentan los siguientes valores guía: $126 \mathrm{NMP} / 100 \mathrm{ml}$ para coliformes fecales y/o E. coli y $33 \mathrm{NMP} / 100 \mathrm{ml}$ de Enterococos. En esta ocación, es importante señalar que el 63,6\% y el 95,4\% de los muestreos no cumplieron con los valores guías para E. coli y para EF, respectivamente.

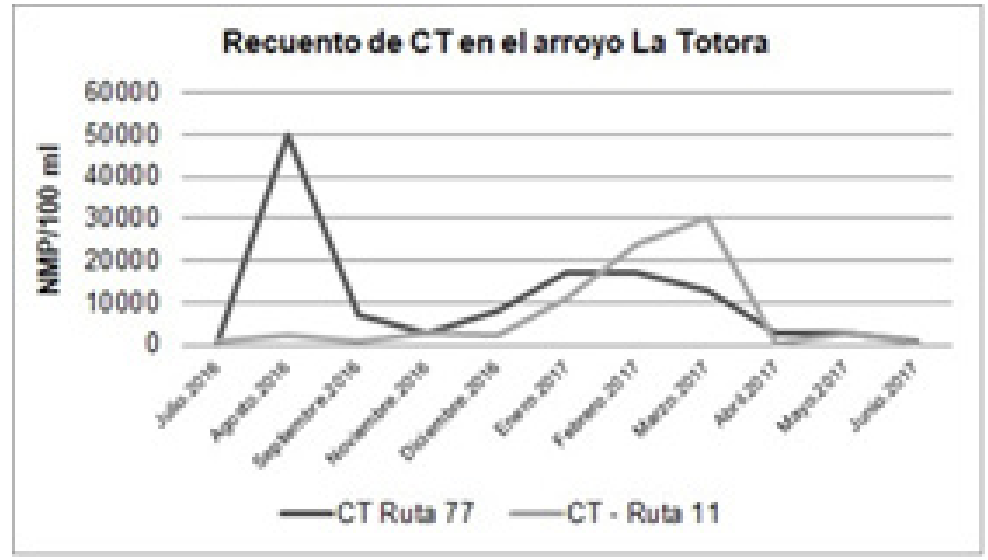


Gráfico N 1: CT en el arroyo La Totora

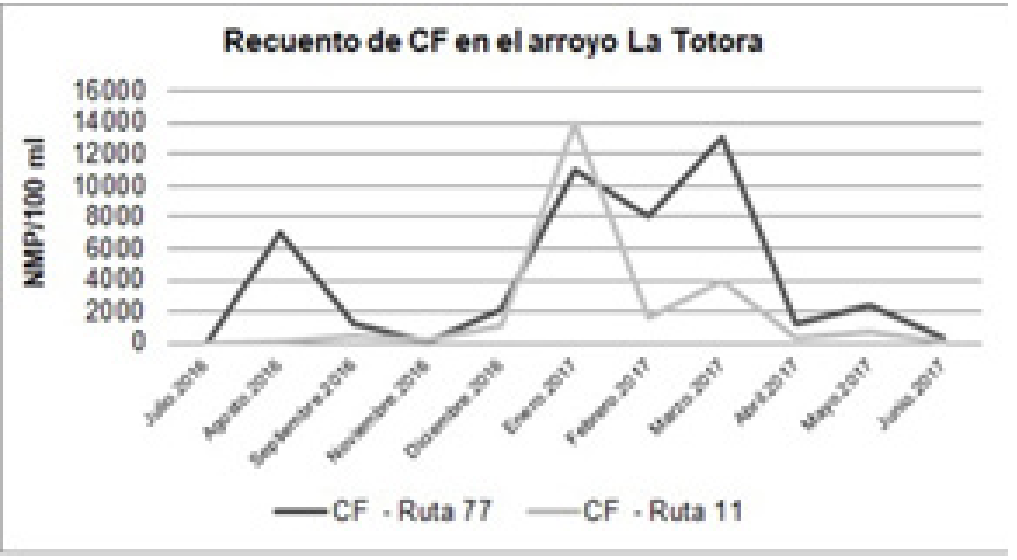

Gráfico N²: CF en el arroyo La Totora

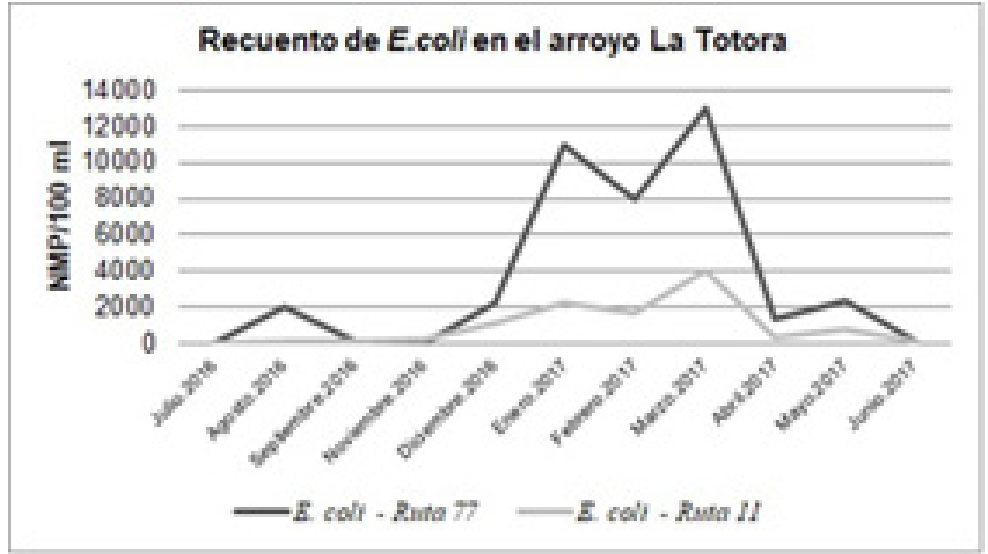

Gráfico № 3: E. coli en el arroyo La Totora

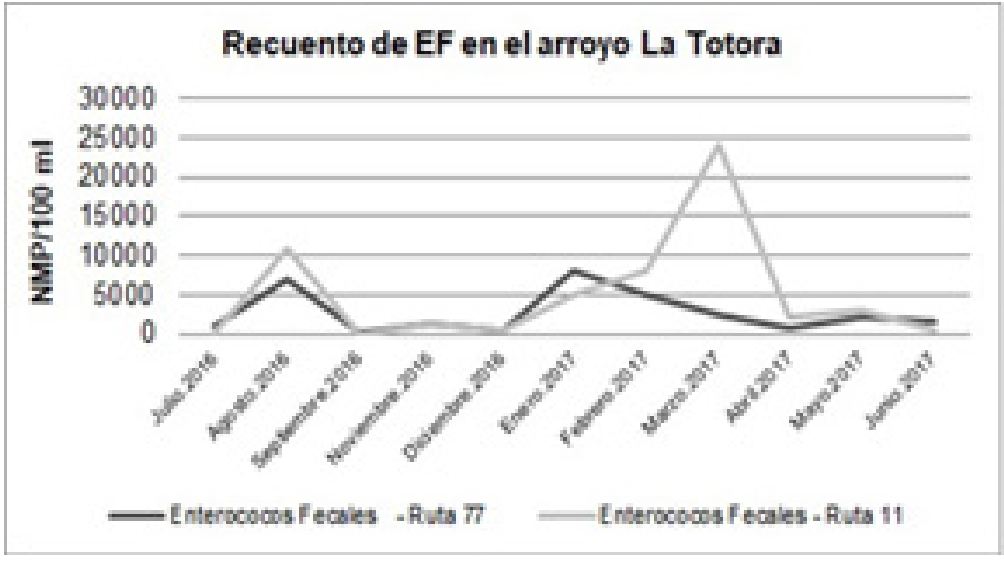

Gráfico N 4: EF en el arroyo La Totora

100 EvaluacióndelaContaminaciónMicrobiológicaPresenteenlosArroyosLaCarolnayLaTotoraUbicadoseneiPartidodeGral_AlvaradoProvidBuenosAires.Argentina 


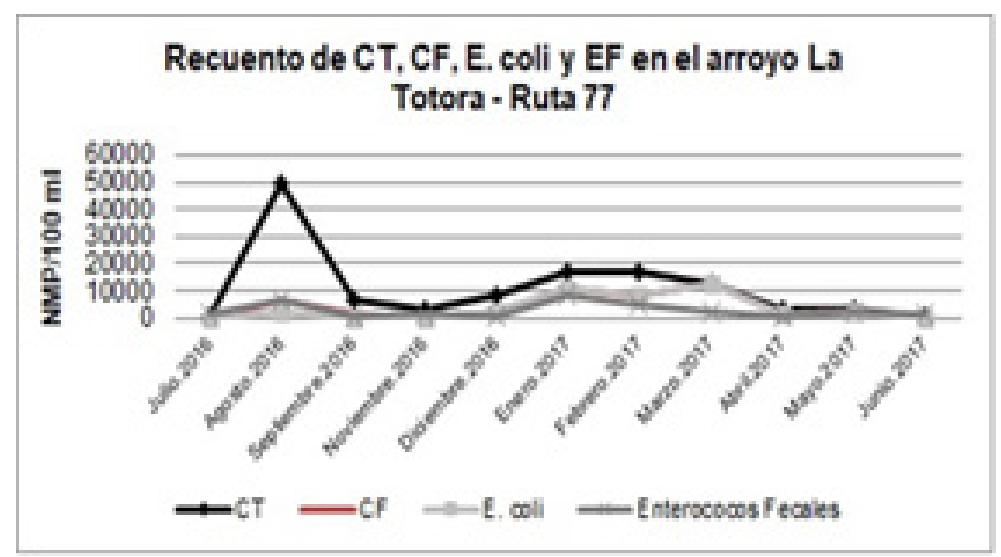

Gráfico N 5: CT, CF, E. coli y EF en el arroyo La Totora - Ruta77

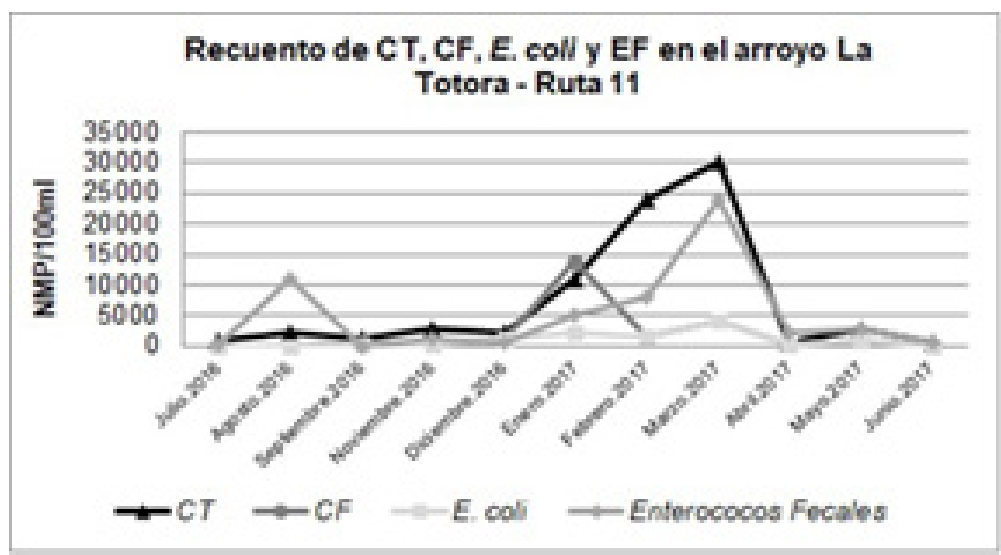

Gráfico N 6: CT, CF, E. coli y EF en el arroyo La Totora - Ruta 11

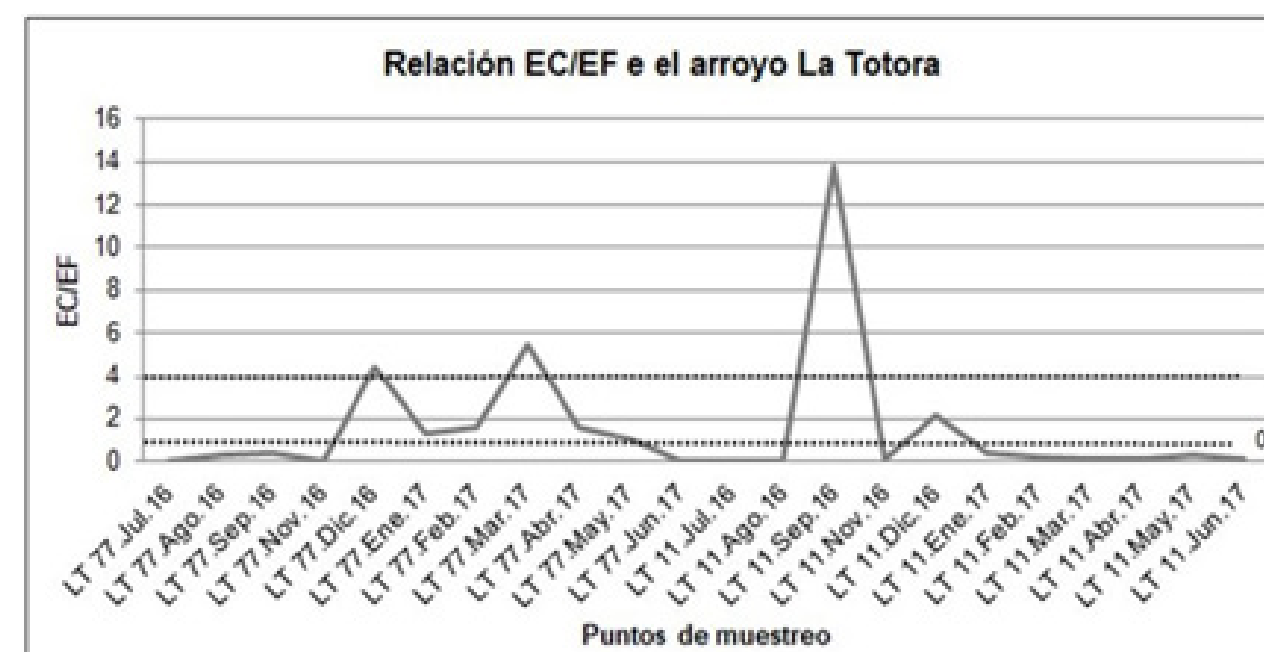

Grafico N 7: Relación EC/EF en el arroyo La Totora 
Los resultados obtenidos en el arroyo La Carolina, se presentan los Gráficos del $\mathrm{N}^{\circ} 8$ al 14. Los mismos son similares a los presentados para el arroyo La Totora pero difieren los meses donde se presentan los puntos más elevados de recuento. En el mes de enero del 2018 se presentaron los mayores recuentos de CT y EF en ambos puntos de muestreo (Gráficos $\mathrm{N}^{\circ} 8$ y 11), mientras que en el mes de febrero se observaron los recuentos elevados de CF y E. coli (Gráficos $\mathrm{N}^{\circ} 9$ y 10). Esto podría deberse al aumento de la población debido al turismo de la zona de estudio.

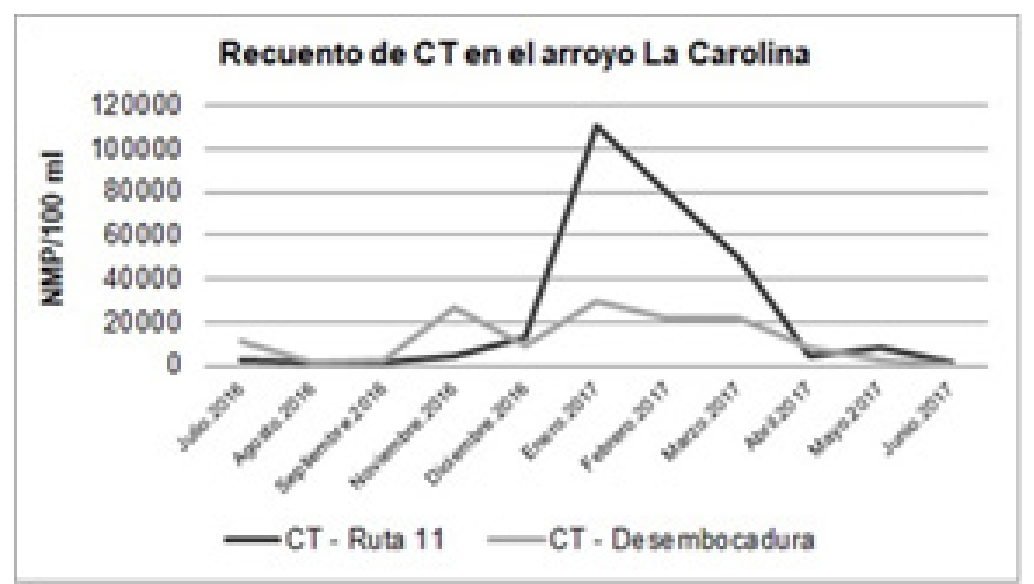

Gráfico Nº 8: CT en el arroyo La Carolina

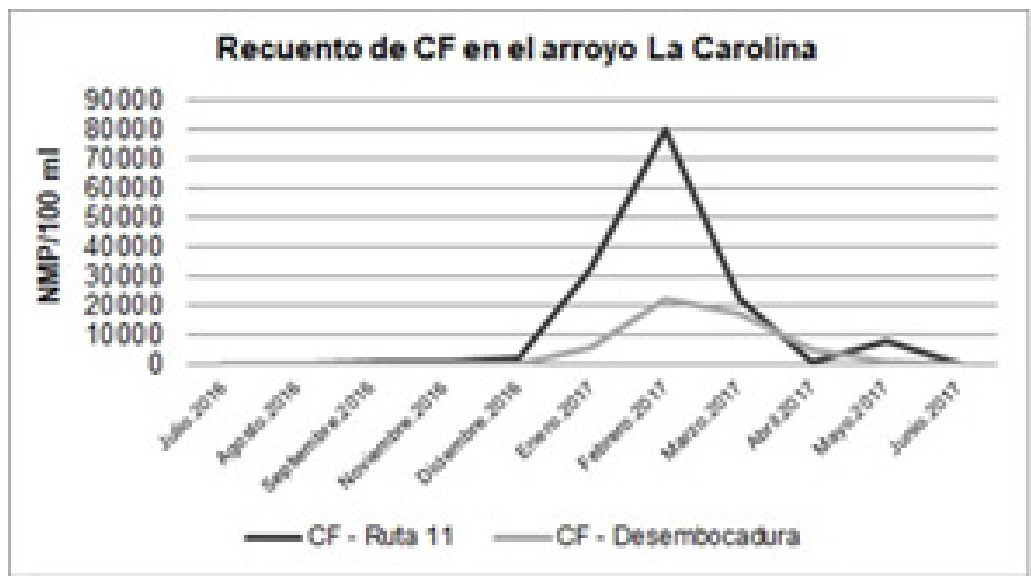

Gráfico Nº 9: CF en el arroyo La Carolina 


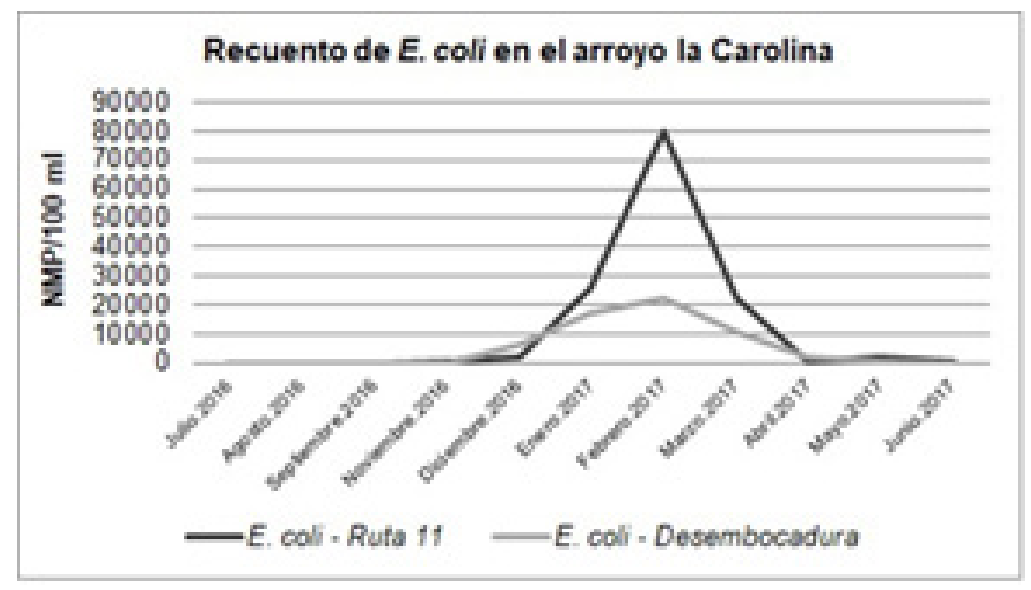

Gráfico N 10: E. coli en el arroyo La Carolina

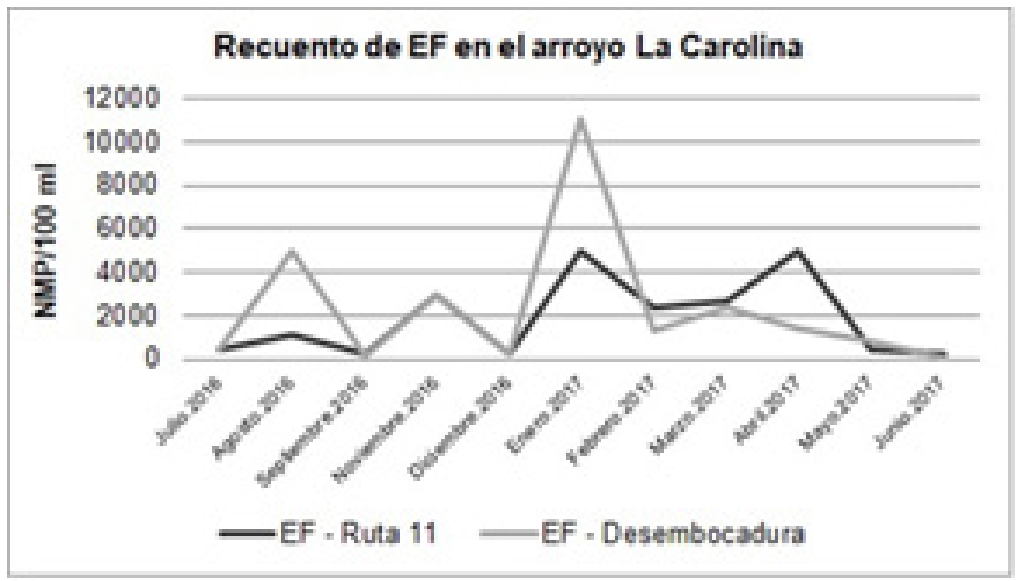

Gráfico № 11: Enterococos fecales en el arroyo La Carolina

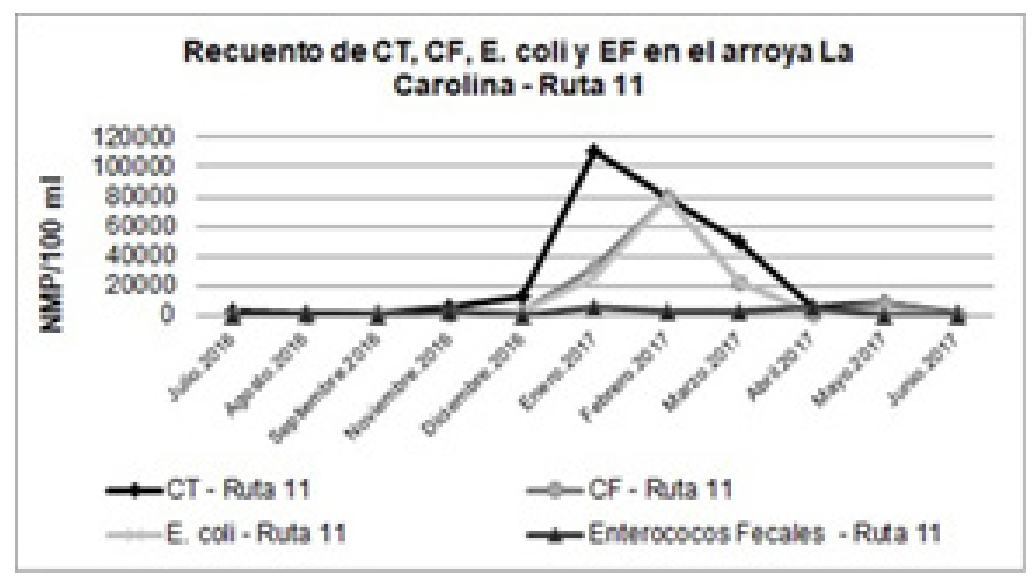

Gráfico No 12: CT, CF, E. coli y EF en el arroyo La Carolina - Ruta 11 


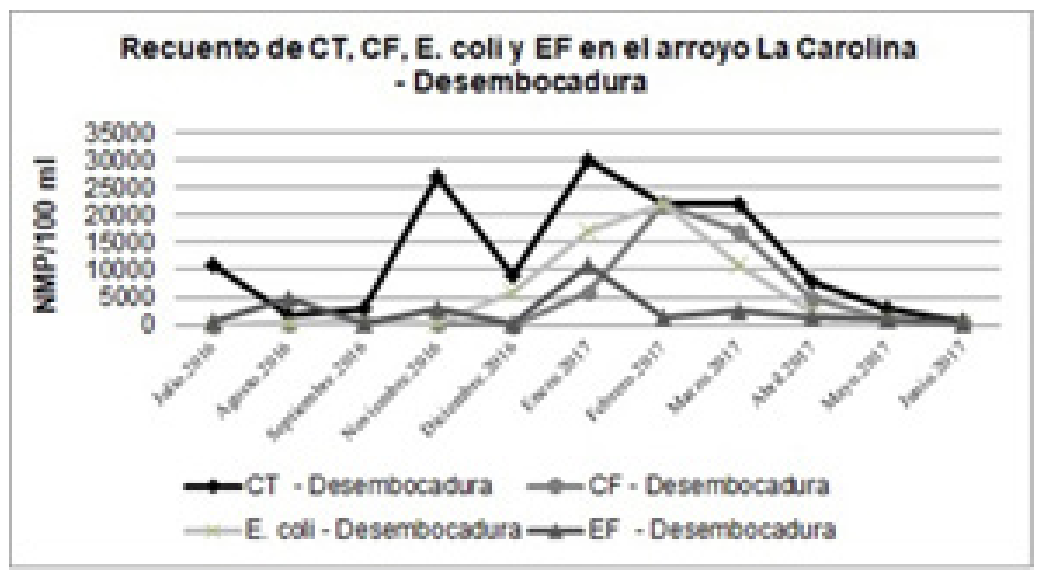

Gráfico No 13: CT, CF, E. coli y EF en el arroyo La Carolina - Desembocadura

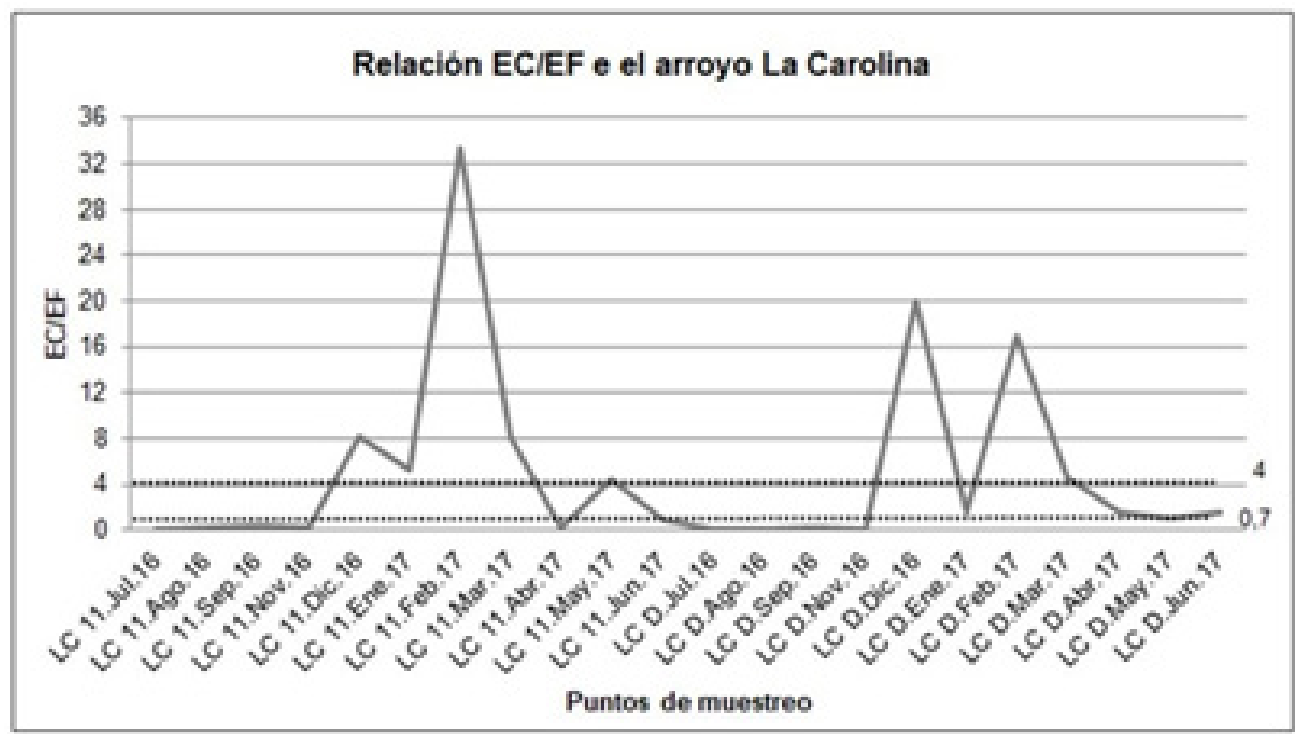

Grafico N 14: Relación EC/EF en el arroyo La Carolina

Con respecto a la proporción EC/EF, los resultados obtenidos en el arroyo La Carolina indican que en 9 muestreos (40.9\%) se observó contaminación de origen animal, 5 muestreos $(22.7 \%)$ presentaron contaminación mixta, mientras que solo 8 muestreos (34.6\%) presentaron un origen humano de la contaminación (Gráfico $\mathrm{N}^{\circ}$ 14). Si comparamos este arroyo con el arroyo La Totora, podemos observar una disminución marcada de la contaminación de origen animal, seguido de un aumento relevante de la contaminación de origen humano. Esto puede deberse a que éste arroyo atraviesa una zona urbana que si bien no tiene una alta población, podría incidir en el aumento de la contaminación fecal. Por otro lado, esta tendencia se ve más aumentada en los meses de mayor afluencia turística en la zona. Esto no concuerda con lo observado por Campins et. al., (2017) para los arroyos 
La Carolina y La Tigra, ellos detectaron que la contaminación de origen humana aumento considerablemente en el mes de diciembre, previo a la concurrencia del turismo en la zona y durante los meses de enero y febrero del 2012 los valores bajaron considerablemente. Es importante señalar que la relación EC/EF ha sido cuestionada, debido a los diferentes índices de supervivencia en los distintos géneros de bacterias indicadoras de contaminación fecal (Boehm y Yamahara, 2009; Davies y Evison, 1991; Boehm y Sassoubre, 2014).

Si comparamos los valores obtenidos en este arroyo con los valores guía de la Resolución 42/06 del Directorio de la Autoridad del Agua de la Prov. de Buenos Aires, ocurre algo similar que lo ocurrido en el arroyo La Totora. En este caso, el $72,7 \%$ no cumplen con lo establecido para E. coli y el $100 \%$ de los mismos no cumplen para EF. Como se menciono anteriormente, si bien los valores son guía, en importante remarcar que se obtuvieron recuentos altos de ambos indicadores, pudiendo ser esto perjudicial para las personas que tengan contacto con estas aguas superficiales.

\section{CONCLUSIONES}

El empleo de las bacterias indicadoras de contaminación fecal continúa resultando de gran utilidad en el monitoreo de la calidad de las aguas. Dentro del grupo de bacterias indicadoras, E. coli constituye un buen indicador de contaminación fecal y combinada con otros indicadores como los enterococos puede brindar una mayor información acerca de las fuentes de contaminación del agua. Cabe remarcar que los valores de los distintos parámetros de estudio no presentaron fluctuaciones significativas a lo largo del muestreo. Sin embargo, en la mayoría de los casos los valores de recuento de E. coli y Enterococos fecales superaron aquellos propuestos por la Resolución 42/06 del Directorio de la Autoridad del Agua de la Prov. de Buenos Aires.

Con respecto al origen de la contaminación, el arroyo La Carolina presentó aumento considerado de contaminación de origen humano en comparación con el arroyo La Totora. Este aumento, como se menciona anteriormente se correlaciona al aumento de la población debido a que es zona de afluencia turística. 


\section{REFERENCIAS}

ONU (Organización de las Naciones Unidas); (1992), Departamento de Economía y Asuntos Sociales: División para el Desarrollo Sostenible. Río de Janeiro: Agenda 21.

Martínez Romero A., Fonseca Gómez K., Ortega Sánchez J.L. and García-Luján C. (2009) "Monitoreo de la calidad microbiológica del agua en la cuenca hidrológica del Río Nazas, México”, Revista QuímicaViva - Número 1, año 8, quimicaviva@ qb.fcen.uba.ar

Bachoon D.S., Markand S., Otero E., Perry G. and Ramsubaugh A., (2010) "Assessment of non-point sources of fecal pollution in coastal waters of Puerto Rico and Trinidad", Marine Pollution Bulletin; 60:1117-1121.

Luby S.P., Gupta S.K., Sheikh M.A., Johnston R.B., Ram P.K. and Islam M.S., , (2008)"Tubewell water quality and predictors of contamination in three floodprone areas in Bangladesh", Journal of Applied Microbiology; 105:1002-1008, (2008).

Méndez R.I., San Pedro L., Castillo E.R. and Vázquez E.B., (2010)“Modelación del tiempo de conservación de muestras biológicas de agua”, Revista Internacional de Contaminación Ambiental; 26 (4):327-335.

Del Pilar M., Ávila S., Mónica S. and Gómez A.C., (2005) “Indicadores microbiológicos de contaminación de las fuentes de agua”. NOVA - Publicación Científica; 3(4):1794-2470.

Ávila de Navia S.L. and Estupiñan S.M., (2009) "Calidad sanitaria del agua de la Ciénaga Mata de Palma en el Departamento del Cesar, Colombia”, NOVA; 7(11):8591. .

Rossen A., Rodríguez M.I., Ruibal A.L., Fortunato M.S., Bustamante A., Ruiz M., Angelaccio C. and Korol S., (2008)"Indicadores bacterianos de contaminación fecal en el embalse San Roque (Córdoba, Argentina)”. Higiene y Sanidad Ambiental; 8:325-330.

Santiago-Rodríguez T.M., Tremblay R.L., Toledo-Hernández C., González-Nieves J.E., Ryu H., Santo Domingo J.W. and Toranzos G.A., (2012) "Microbial quality of tropical inland waters and effects of rainfall events", Applied and Environmental Microbiology; 78(15):5160-5169.

Delgado Y., Miravet M.E. and Núñez R., (2008) “Indicadores microbiológicos de calidad del agua en la costa oeste de la Ciudad de La Habana”, Higiene y Sanidad Ambiental; 8:387-391.

Carrillo E.M. and Lozano A.M., (2008)"Validación del método de detección de coliformes totales y fecales en agua potable utilizando Agar Chromocult”. Tesis (Microbióloga Industrial), Facultad de Ciencias., Microbiología Industrial, Pontificia Universidad Javeriana, Bogotá, Colombia, 97.

Larrea Murrell J.A., Rojas Badía M.M., Romeu Álvarez B., Rojas Hernández N.M. and Heydrich Pérez M., (2013) "Bacterias indicadoras de contaminación fecal en 
la evaluación de la calidad de las aguas”, Revista CENIC, Ciencias Biológicas; vol. 44, núm. 3, pp. 24-34.

Badgley B.D., Thomas F.I.M. and Harwood V.J., (2011) "Quantifying environmental reservoirs of fecal indicator bacteria associated with sediment and submerged aquatic vegetation”, Environmental Microbiology; 13 (4):932-942.

Chiroles S.R., González M.I., Torres T., Valdés M. and Domínguez I., (2007) "Bacterias indicadoras de contaminación fecal en aguas del río Almendares (Cuba)”. Higiene y Sanidad Ambiental;(7):222-227.

Narváez S., Gómez M. and Acosta J., (2008) “Coliformes termotolerantes en aguas de las poblaciones costeras y palafíticas de La Ciénaga Grande de Santa Marta, Colombia”, Acta Biológica Colombiana; 13(3):111-120.

Ministerio de Agua, Ambiente y Servicios Públicos Provincia Córdoba.(Julio 2016) Decreto $847 / 16$. Normas para la protección de los recursos hídricos superficiales y subterráneos.

Köhler W., (2007) "The present state of species within the genera Streptococcus and Enterococcus”, International Journal of Medical Microbiology; 297(3):133-50.

Díaz M., Rodríguez C. and Zhurbenko R., (2010) "Aspectos fundamentales sobre el género Enterococcus como patógeno de elevada importancia en la actualidad", Revista Cubana de Higiene y Epidemiologia; 48(2):47-161.

Yamahara K.M., Walters S.P. and Boehm A.B., (2009) "Growth of enterococci in unaltered, unseeded beach sands subjected to tidal wetting", Applied Environmerntal Microbiology; 75:1517-1524.

Díaz Á.M., Izquierdo C.S., Fernández de la Paz T. and Izquierdo A.M. , (2008) "Características clínicas y epidemiológicas de las infecciones por enterococos en el niño”, Revista Cubana de Pediatría; 79(1).

Martín A.V. and García M.C., (2009) "Contaminación química de aguas para consumo en la periferia urbana de la localidad de Miramar, Provincia de Buenos Aires, Argentina”. Nadir: Revista Electrónica de Geografía Austral Universidad Autónoma de Chile; vol (1):12-30. ISSN: 0718-7130..

Del Rio J.L., Benseny G., Oyarbide F., Camino M.A., Bó M.J, Padilla N.A. and De Marco S., (2017) "El paisaje fluvial en escenarios urbanos y periurbanos en el sudeste de la provincia de Buenos Aires - Argentina”, Água, recurso hídrico: bem social transformado em mercadoria Tupã: Associação Amigos da Natureza da Alta Paulista (ANAP); Cap 9: 192-213.

Islas F.I., (2003) "Disponibilidad de arena para el refulado de las playas de Miramar y Chapadmalal, Argentina”, Revista de la Asociación Geológica Argentina; 58 (3): 311-320.

AWWA, APHA, WEF. , (2012) Standard Methods for the Examination of Water and Wastewater. 22th edición.

Faddin Jean M.A.C. , (2003)“Pruebas Bioquímicas para la identificación de bacterias de importancia clínica”. Panamericana; Tercera Edición Argentina. 
Tchobanoglous G., Burton F.L. and Stensel H.D., (2003) "Wastewater engineering treatment and reuse”. Ciudad Metcalf and Eddy Inc., McGraw Hill; 4th ed..

Meeroff D.E., Bloetscher F., Bocca T.and Morin F., (2008) "Evaluation of water quality impacts of on-site treatment and disposal systems on urban coastal waters", Water Air Soil Pollut; 192:11-24.

Marchand E.O., (2002) "Microorganismos indicadores de la calidad del agua de consumo humano en Lima Metropolitana”, Tesis (Biólogo con mención en Microbiología y Parasitología). Universidad del Perú, Decana de América, 71.

Coyne M.S. and Howell J.M., (1994)“The fecal coliform/fecal streptococci ratio (FC/FS) and water quality in the Bluegrass Region of Kentucky". Soil and Science News and Views; 15(9):1-8.

Resolución 42/06 del Directorio de la autoridad del agua de la Prov. de Buenos Aires. http://www.ada.gba.gov.ar/normativa/RESOLUCIONES/RESOL042-2006/ RESOL042-2006-ANEXOII.pdf

Campins M., Rampi M., Del Rio J. and Zamora A., (2017) "Estudio de la contaminación presente en los arroyos la tigra y la carolina y su incidencia en la playa adyacente en mar del sud. Gral. Alvarado. Prov. de Buenos Aires. Argentina. Acta del Congreso PROIMCA - PRODECA, Bahía Blanca, Argentina, 6 al 7 de septiembre de 2017.

Boehm A. and Yamahara K., (2009 "Covariation and photoinactivation of traditional and novel indicator organisms and human viruses at a sewage impacted marine beach", Environmental Scice and Technology; 43 (21) 8046).

Davies C. and Evison L., (1991) "Sunlight and the survival of enteric bacteria in natural-waters”, Journal Applied Bacteriology; 70 (3) p 265-274.

Boehm A. and Sassoubre L., (2014) "Enterococci as Indicators of Environmental Fecal Contamination. In: Gilmore MS, Clewell DB, Ike Y, et al., editors. Enterococci: From Commensals to Leading Causes of Drug Resistant Infection. Boston: Massachusetts Eye and Ear Infirmary. 